\title{
Posguerra y posverdad: La condición masónica de Margarita Nelken
}

\section{Post-war and Post-Truth: The Masonic Affiliation of Margarita Nelken}

\author{
Pelayo Jardón Pardo de Santayana \\ Universidad de Educación a Distancia, España \\ pelayojardon@yahoo.com
}

Recepción: 15 de abril de 2019/Aceptación: 8 de mayo de 2019.

doi: https://doi.org/10.15517/rehmlac.v11i1.36956

Palabras clave

Masonería, represión, franquismo, guerra civil española, feminismo.

Keywords

Freemasonry, Repression, Franco Regime, Spanish Civil War, Feminism.

\section{Resumen}

Tras la Guerra Civil española, la diputada Margarita Nelken (1893-1968) fue juzgada por el Tribunal para la Represión de la Masonería y el Comunismo. Fue acusada de los delitos de masonería y comunismo y procesada en rebeldía. Se señalaron como indicios de masonería su relación con la Institución Libre de Enseñanza y su participación en la Liga de los Derechos del Hombre. La principal prueba física del sumario era una carta de recomendación de la logia Lealtad, de Barcelona, fechada en 1924, que en realidad correspondía a la cupletista Stella Margarita. Pese a la falta de pruebas, se consideró en la sentencia que Margarita Nelken había ingresado en la masonería, a la que había dispensado "protección importante".

Abstract

After the Spanish Civil War, the representative Margarita Nelken (1893-1968) was tried by the Special Tribunal for the Repression of Freemasonry and Communism. She was accused of the crimes of Freemasonry and communism and judged by default. Her connections with organizations such as the Free Institute of Education and the Spanish League of Human Rights were taken as hints that she was a member of Freemasonry. The only physical evidence her accusers had was a recommendation letter issued by the Barcelonese lodge Lealtad in 1924. However, the letter didn't belong to her, but to a cabaret singer named Stella Margarita. Despite the lack of evidence, she was found guilty of having joined Freemasonry.

Entre los procesos que se resolvieron ante el Tribunal Especial para la Represión de la Masonería y el Comunismo, merece especial atención uno que podría resultar revelador acerca de ese hipotético contubernio judeo-masónico-comunista, al cual pretendió desenmascarar el régimen del general Franco. Nos referimos al juicio seguido contra Margarita Nelken (1894-1968), política española de origen judío, miembro del Partido Socialista y después del Partido Comunista, a la que se acusó de haber sido iniciada en la masonería. La encausada se contaba a la sazón entre las mujeres que mayor notoriedad habían alcanzado en España. Junto a Clara Campoamor y Victoria Kent, había sido una de las tres 
primeras diputadas de la historia parlamentaria española. Además, fue la única mujer presente como tal en las tres legislaturas republicanas.

Nacida en 1894 en Madrid ${ }^{1}$ — que no en Alemania, como consta en su expediente del tribunal-, Nelken procedía de una familia acomodada de origen judío, en parte centroeuropeo y en parte franco-sefardí. Su padre y su abuelo materno tenían un próspero negocio de joyería y relojería en la Puerta del Sol. Parece ser que su ascendencia semita dificultó la integración social de Nelken. Sin embargo, la desahogada situación económica familiar le permitiría acceder a una esmerada educación. Estudió pintura en el taller madrileño de Eduardo Chicharro, y después en París. Aunque no llegó a dedicarse profesionalmente a la pintura, tales estudios le sirvieron como base para dedicarse a la crítica artística desde comienzos de la década de 1910. Además, entre los años 1916 y 1920, coincidiendo con el boom feminista propiciado por la I Guerra Mundial, escribió artículos sobre los derechos femeninos en periódicos como El Día, El Fígaro y La Libertad, en los cuales trató sobre la realidad social y jurídica a la que tenía que enfrentarse la mujer. Estos artículos darían lugar a su obra más famosa: La condición social de la mujer en España, publicada en $1921^{2}$.

Concienciada políticamente de su juventud, influida por las lecturas de Flora Tristán y de Auguste Bebel, Nelken militó en las filas de un feminismo de izquierdas, que proclamó como única alternativa válida al sufragismo liberal, por un lado, y al feminismo católico, por otro. Abogó por los derechos de las trabajadoras —obreras, artesanas, maestras, modistasy también por los de las mujeres socialmente marginadas, como prostitutas y convictas. Considerando a la Iglesia una enemiga soterrada de las reivindicaciones feministas, se identificó con las políticas laicistas, cuando no anticlericales. El objetivo de la Iglesia no era, a su juicio, la emancipación femenina; sino que, al contrario, trataba de mantener a la mujer en la ignorancia y la sumisión, para consolidar las bases de su propio poder temporal. Partiendo precisamente de esa dependencia moral de la mujer respecto de la Iglesia, Nelken preconizó el aplazamiento de la concesión de sufragio femenino activo hasta que la mujer recibiera una educación política, laica y progresista, que le permitiera ejercer el derecho al voto libre de condicionamientos religiosos.

En el otoño de 1931 fue elegida diputada por el Partido Socialista en la circunscripción de Badajoz. Pese a lo que, dada su trayectoria anterior, habría cabido esperar, su carrera política no se proyectó en la defensa de los derechos de la mujer, sino en los problemas que aquejaban a sus electores del campesinado pacense. En cualquier caso, Nelken

\footnotetext{
${ }^{1}$ Partida de nacimiento de Margarita Nelken; inscrita el 6 de julio de 1894, con el no. 430 en el Juzgado Municipal del distrito de Audiencia, de Madrid (Archivo Histórico de la Villa de Madrid). Pelayo Jardón Pardo de Santayana, Margarita Nelken: del feminismo a la revolución (Madrid: Sanz y Torres, 2013).

${ }^{2}$ Margarita Nelken, La condición social de la mujer en España. Su estado actual, su posible desarrollo (Barcelona: Editorial Minerva, 1921). Reeditada con prólogo de M. A. Campmany (Madrid: CVS Ediciones, 1975).
} 
alcanzó gran notoriedad como diputada socialista y ello le atraería las iras de los reaccionarios. Podían perdonarle sus artículos feministas, pero no que, para defender su ideario socialista, saliera a la palestra política en pie de igualdad con otros hombres. Es entonces cuando empiezan a arreciar los ataques contra ella, como, por ejemplo, el de Ramiro de Maeztu, quien, en un artículo de 1935, y aludiendo ya al tan traído y llevado contubernio, la acusó de mover sus influencias entre judíos y masones para conspirar contra el gobierno de Lerroux ${ }^{3}$.

Durante la Guerra Civil, Nelken desplegó una intensa actividad en pro de la España republicana. Se desplazó hasta los frentes en la sierra de Madrid y participó en mítines propagandísticos y foros internacionales, como el Comité Mundial de Mujeres contra la Guerra y el Fascismo. Su compromiso con la República no le restó, empero, un ápice de su carácter contestatario e indómito. Como consecuencia de su enfrentamiento con Largo Caballero, a finales de 1936 abandonó el PSOE para pasar al Partido Comunista. Posteriormente continuaría desplegando una actividad febril, tanto desde su tribuna periodística en Mundo Obrero, como a través de su participación en numerosos actos públicos dentro y fuera de España. No es, pues, de extrañar que se convirtiera en blanco de las iras de los nacionales, cuyos corifeos la dirigieron toda suerte de injurias, como Juan Pujol, quien la calificaría de "vagabunda sin patria y sin Dios" y de "serpiente con faldas"4. De modo parecido, otros autores como Edgar Neville o Francisco Casares, en su libro Azaña y ellos, la atacarían como denigrante ejemplo de esas "rojas", baldón de ignominia para el nuevo régimen ${ }^{5}$.

Como es sabido, al término de la contienda las autoridades franquistas impulsaron un proceso de severa depuración política, orquestado a partir de la Ley de 1939 de Responsabilidades Políticas y de la Ley de 1940 para la Represión de la Masonería y el Comunismo. Habida cuenta de la trayectoria que la precedía, Nelken fue procesada con arreglo a tales leyes. Un examen pormenorizado del sumario arroja luz sobre ese metódico simulacro de la justicia de posguerra, sobre la aparente minuciosidad de una práctica forense que, en puridad, ofrecía escasas, si no nulas, garantías jurídicas ${ }^{6}$.

El 17 de julio de 1941, un tribunal presidido por el teniente general Andrés Saliquet (1877-1959), y compuesto por el general Francisco de Borbón y de la Torre (1882-1952), el político carlista Marcelino Ulibarri Eguilaz (1880-1951), y el catedrático de Filosofía del

\footnotetext{
${ }^{3}$ Ramiro de Maeztu, “¡Es la Nelken!”, en $A B C, 1$ de febrero de 1935, 3.

${ }^{4}$ Juan Pujol, "Galería de monstruos: La serpiente con faldas", en $A B C$, Sevilla, 17 de febrero de 1937, 3.

${ }^{5}$ Edgar Neville, "Margarita Nelken o la maldad", en Y: Revista para la mujer, no. 8, septiembre de 1938, 12; Francisco Casares, Azaña y ellos. Cincuenta semblanzas rojas (Granada: Editorial y Librería Prieto, 1938), 197200.

${ }^{6}$ Sumario n. ${ }^{\circ} 83$ del año 1941, del Juzgado Instructor Especial n. ${ }^{\circ} 2$, correspondiente al n. ${ }^{\circ} 207$ del tribunal seguido contra el procesado en rebeldía Margarita Nelken de Paúl. Centro Documental de la Memoria Histórica, Salamanca. Ref.: ES.37274.CDMH/7//TERMC, 207.
} 
Derecho, Wenceslao González Oliveros (1890-1965), acordó que pasara el expediente de Nelken al juez correspondiente a efectos de incoación de sumario.

Mediante providencia de 29 de agosto de 1941, el juez Tomás Pereda Iturriaga decretó prisión provisional contra Nelken. Como esta se hallaba en paradero desconocido, ordenó que se la llamara por requisitoria para que compareciera en el Juzgado a fin de ingresar en prisión. El 19 de octubre de 1941 se publicó tal requisitoria en el $\mathrm{BOE}^{7}$. Ocho días después se la declaró en busca y captura y se expidió oficio al Director General de Seguridad para que remitiera los antecedentes masónicos y político-sociales de la inculpada.

Dichos antecedentes masónicos figuraban en un certificado firmado el 14 de julio de 1941 por José Gómez Hernández, jefe de la Sección Especial de Recuperación de Documentos $^{8}$. La única prueba física que se aportaba era una carta de presentación que la logia "Lealtad" n. ${ }^{\circ} 6$ de Barcelona había dirigido a la Gran Logia Regional del Nordeste de España, fechada el 27 de agosto de 1924, en la cual se solicitaba que se extendiera una carta de recomendación "a nombre de nuestra querida hermana Margarita, la que va a los Valles de Milán en viaje profesional lo que os recomendamos con el mayor interés pues quizá nuestra querida hermana Margarita necesite de este documento para orientarse en la vida masónica de Italia".

Nótese, pues, que, sin entrar en mayores honduras, se identificó lisa y llanamente a Margarita Nelken con la "hermana Margarita" y que, en consecuencia, se infirió que había sido iniciada en la masonería con anterioridad a la fecha de tal recomendación. Tal conjetura, cimentada exclusivamente en la carta de 1924, no venía avalada por otros datos de la condición masónica de la procesada, como su nombre simbólico o fecha de iniciación. Además, cabría preguntarse si, en efecto, Nelken había realizado ese viaje a Milán, del que no tenemos constancia, o por qué, siendo vecina de Madrid y no habiendo residido hasta entonces en la Ciudad Condal, habría tomado la decisión de iniciarse en una logia de Barcelona y no en una de la Villa y Corte. Profundizando en la cuestión, resulta interesante consultar el trabajo sobre las logias catalanas, en el que Sánchez i Ferré estudia la admisión de mujeres en la logia Lealtad a partir de 1879. Incluye este autor un listado de las mujeres de la cámara de adopción de esta logia, entre las que se encontraban la profesora Aurora Rosa Clavé de Ferrer — simbólico, Mariana Pineda - o la arpista Clotilde Cerdá, más conocida como Esmeraldina Cervantes y cuyo nombre simbólico era Esther. Pues bien: no hay documentación que certifique la admisión de nuevas mujeres entre 1885 y 1939, a excepción de un solo documento, del 31 de agosto de 1923, en el cual se notificaba que el 10 de julio se había procedido a la exaltación al grado tercero del rito de adopción de la "Hermana Stella Margarita". Considera prudentemente Sánchez i Ferré que no hay ninguna prueba que

\footnotetext{
${ }^{7}$ Requisitoria n. ${ }^{\circ}$ 4957. BOE, p. 3480, año VI. n. ${ }^{\circ} 262$.

${ }^{8}$ Archivo Masónico, de la Comisaría General de Información, de la Dirección General de Seguridad. Expediente personal de Margarita Nelken, Exp. 17 A, Leg. 19.
} 
evidencie que la aludida fuera Margarita Nelken ${ }^{9}$. Las reservas de Sánchez i Ferré están más que fundadas si tenemos en cuenta que la iniciada en la logia Lealtad no fue otra que la cupletista española, radicada en Tenerife, Margarita Iglesias, más conocida por su nombre artístico de Stella Margarita, esposa del cantante y también masón José Mariné Gomis, con el que actuaba desde comienzos de la década de $1910^{10}$. La fotografía de esta cantante, dedicada en 1921 a sus hermanos del Supremo Consejo de "Canarius, n. ${ }^{\text {" } 12 ", ~ q u e ~ s e ~ c o n s e r v a ~}$ en el Centro Documental de la Memoria Histórica, revela que, con independencia de cierta semejanza física y del mismo aire de época, no se trata en ningún caso de Margarita Nelken ${ }^{11}$.

Asimismo, en el informe sobre los antecedentes masónicos de Nelken, se añadía que había sido vocal de la Junta Reorganizadora de la Liga de los Derechos del Hombre, y se citaba como prueba la página 24 del Boletín número 1 de dicha institución, de 1933. Como es sabido, la Liga Española para la Defensa de los Derechos del Hombre y del Ciudadano se había constituido en Madrid en 1913, a instancias de una campaña orquestada por todas las confesiones no católicas, por la masonería y por los partidos políticos, que, a raíz especialmente de la ejecución de Ferrer, preconizaban la libertad de conciencia. El Comité de esta Liga, presidido por Luis Simarro, contaba entre sus miembros a masones - Augusto Barcia Trelles, Nicolás Salmerón y el propio Simarro-, si bien otros de sus fundadores entre los que cabría destacar a Benito Pérez Galdós, Rafael Salillas o Laureano Miró- no pertenecían a la masonería. Tras diversas vicisitudes la Liga fue refundada el 1 de marzo de 1922. Se encomendó a una nueva Junta Nacional, entre cuyos miembros se encontraba ya Margarita Nelken, la tarea de revitalizar la Liga, proyecto que finalmente no llegó a cuajar por mor de la dictadura de Primo de Rivera. La Liga volvió, empero, a renacer en la II República, bajo la presidencia de Unamuno y la participación de muchas personalidades que ya habían sido miembros en 1923, como la propia Nelken. De todo lo dicho, podemos concluir que, en efecto, la encausada había pertenecido a la Liga en sus refundaciones de 1922 y 1931. Sin embargo, y pese a la proximidad de esta institución a la Orden, como atestigua que casi un tercio de sus miembros fueran masones, lo cierto es que la afiliación de Nelken a la Liga no puede considerarse como prueba o indicio de masonería.

\footnotetext{
${ }^{9}$ Pere Sánchez i Ferré, La Lògia Lealtad. Un exemple de Maçoneria catalana 1869-1939 (Barcelona: Ed. Altafulla, 1985), 72-75.

${ }^{10}$ Centro Documental de la Memoria Histórica, Salamanca. Sumario 1277-44 contra Margarita Stella por delito de masonería. Ref.: ES.37274.CDMH/7//TERMC,11351. Sumario 1333-44 contra José Mariné Gomis por delito de masonería. Ref.: ES.37274.CDMH/7//TERMC,11513. Para los inicios de la pareja en el mundo del espectáculo, vid., entre otras muchas, las siguientes reseñas: Madrid Cómico, n. ${ }^{\circ} 137,13$ de octubre de 1912, 16; La prensa: diario republicano: n. $^{\circ}$ 764, 7 de febrero de 1913, 2; La Opinión: periódico político y de intereses generales, n. $^{\circ} 6133,8$ de febrero de 1913, 1; etc.

11 Centro Documental de la Memoria Histórica, Salamanca. Ref.: ES.37274.CDMH//SEMASONERIA_B,FOTO.27. Agradezco este dato a la Dra. Sylvia Hottinger Craig. Vid.: Sylvia Hottinger Craig, "Las fotografías de mujeres entre las fotografías de origen masónico del archivo general de la Guerra Civil española", en Masonería Española. Represión y Exilios, coord. José Antonio Ferrer Benimeli (Almería: Gobierno de Aragón, Departamento de Educación, Cultura y Deporte, 2009), 1417-1430.
} 
De otro lado, se recordaba que Nelken había pertenecido a la Institución Libre de Enseñanza, lo cual, por cierto, tampoco es exacto. Sabemos, eso sí, que en 1919 había solicitado una beca - que no le fue concedida - a la Junta de Ampliación de Estudios de la Residencia de Estudiantes ${ }^{12}$. Conocemos también, por alguno de sus escritos, su relación con alguno de los integrantes de la institución, como Manuel Bartolomé Cossío. No obstante, de estos datos tampoco cabe deducir la pertenencia de Nelken a la masonería. Permítasenos citar, en este sentido, estudios como el de Álvarez Lázaro, el cual, si bien señala los vínculos que hubo entre la masonería, el krausismo y la obra de Giner, descarta la intervención de la masonería en la fundación o mantenimiento de la Institución Libre de Enseñanza ${ }^{13}$. Podemos concluir, pues, que esta circunstancia tampoco evidencia la vinculación de Nelken a la masonería.

De otro lado, y hasta donde llega nuestro conocimiento, Nelken jamás abordó cuestiones masónicas en su obra. Sí ironizó, en cambio, sobre que se la hubiera llegado a relacionar con la masonería. Así lo vemos en El orden, un opúsculo de tipo autobiográfico publicado en 1931, en el que trataba de demostrar la resistencia que había opuesto a la dictadura de Primo de Rivera. A este respecto, recordaba que, con ocasión de un ciclo de conferencias que había impartido en Asturias, había sido sometida, al parecer, a una estrecha vigilancia por parte del Gobernador civil, el cual, ante la sospecha de que formaba parte de una conspiración masónica, republicana y comunista, había cercenado alguno de sus derechos, como la libertad de expresión o la inviolabilidad de la correspondencia ${ }^{14}$. Una cita de similar tenor la encontramos en la obra, ya mencionada, de diez años antes, La condición social de la mujer en España, cuando describe la situación irregular que se vivía en el Asilo de Vallehermoso de Madrid, y su enfrentamiento con las religiosas que lo regentaban, a las que tachó de profesionalmente ineptas y de insolidarias ${ }^{15}$. Pues bien, tales monjas, según comentaría Nelken después, la acusaron, por ello, de haber servido de instrumento de la masonería, extremo que Nelken negó: "Y esto sería risible si no fuera tan trágico"16.

Téngase en cuenta, asimismo, que, de haber sido realmente masona, la condición de personaje público de Margarita Nelken desde su juventud habría propiciado la conservación de más pruebas al respecto, como, de hecho, ocurre con otras mujeres como Carmen de Burgos, cuya filiación masónica sí ha sido probada.

\footnotetext{
${ }^{12}$ Shirley Mangini, Las modernas de Madrid. Las grandes intelectuales españolas de la vanguardia (Barcelona: Ediciones Península, 2001), 205.

${ }_{13}$ Pedro Álvarez Lázaro y José Manuel Vázquez Romero eds., Krause, Giner y la Institución Libre de Enseñanza (Madrid: Publicaciones de la Universidad Pontificia Comillas, 20059.

${ }^{14}$ Nelken, El orden (Madrid: La Novela Roja, Semanario de literatura revolucionaria, 8 de julio de 1931). Reeditada por Talleres poligráficos en 1934. Incluida en el tomo Las novelas rojas, Estudio y antología de Gonzalo Santonja (Madrid: Ediciones de la Torre, 1994).

${ }_{15}$ Nelken, "Carta abierta al Ministro de la Gobernación", en El Día, 15 de julio de 1918, 5. Íd., "Una conversación con la doctora Arroyo de Márquez", en El Día, 26 de julio de 1918, 1. Íd., "La directora de la Escuela Normal", en El Día, 2 de agosto de 1918, 1.

${ }^{16}$ Nelken, La condición social, 156.
} 
En cualquier caso, el 28 de octubre de 1941, Nelken fue declarada procesada y en rebeldía. Para entonces ya se encontraba fuera de España. En febrero de 1939 había pasado a Francia y, tras trabajar unos meses en París, ante la amenaza de la Segunda Guerra Mundial y de la inminente invasión nazi, se había exiliado en México. Ese mismo 28 de octubre de 1941 se declaró, pues, terminado el sumario y listo para pasar al Ministerio Fiscal, el cual declaró su conformidad con los autos de procesamiento, de rebeldía y de conclusión.

Apenas dos semanas después se señaló la celebración de la vista de la causa para el 14 de noviembre a las cinco de la tarde. Dicho día se celebró el juicio en sesión secreta. Presidió el tribunal el general Saliquet; lo compusieron como vocales Wenceslao González Oliveros, el falangista Juan José Pradera Ortega y el general Ricardo de Rada. El Ministerio Fiscal reputó a la procesada como autora con todo género de agravantes de los delitos consumados de masonería y comunismo. Y el tribunal, en fin, acordó unánimemente dictar sentencia condenatoria en los términos de la calificación fiscal. En el primer resultando del fallo se recogió el currículo masónico comunista de la encausada:

"Que la procesada en rebeldía MARGARITA NELKEN DE PAUL ingresó en la Masonería en la Logia "Lealtad" de Barcelona, con anterioridad a 1924 en cuyo año se la recomendaba como afiliada a la secta y en la "Gran Logia Regional del Noroeste (sic) de España" en un viaje que la encartada iba a hacer a los "valles de Milán"'”.

Se señalaba a continuación su afiliación al PSOE, su condición de diputada socialista y su participación en la revolución de 1934, así como la campaña que había realizado en 1935 en favor de los represaliados de Asturias. También se aludía a sus estancias en la Unión Soviética, su pertenencia a la Asociación de Amigos de la URSS y su actividad para implantar el comunismo en España. Nada habría que objetar a la veracidad de estas últimas apreciaciones. Sí resulta, empero, más que discutible la contenida en el último párrafo, donde se afirmaba que la procesada había tratado de llevar a España a la ruina y que, gracias a sus campañas en favor de los "oprimidos rojos", podía permitirse vivir en la abundancia.

El primer considerando fue rotundo, por cuanto en él se recalcó que Nelken había ingresado "en la Masonería, a la que dispensó protección importante - afirmación gratuita donde las haya - sin haber presentado declaración retractación". Y, en lo atinente al comunismo, se añadía que había sido "una inductora dirigente y una destacada propagandista soviética. Por todo ello fue condenada como autora "de un delito consumado de Masonería y Comunismo" a "la pena de treinta años de reclusión mayor y accesorias de interdicción civil e inhabilitación absoluta perpetua para el ejercicio de cualquier cargo del Estado, Corporaciones Públicas u Oficiales, Entidades Subvencionadas y Empresas concesionarias, gerencias y consejos de administración de Empresas privadas, así como cargos de confianza, mando y dirección de las mismas, separándole definitivamente de los mencionados cargos." El 6 de diciembre de 1941 se publicó el fallo en el $\mathrm{BOE}^{17}$ y diez días después se

${ }^{17} \mathrm{BOE}$, n. $^{\mathrm{o}} 340,4513$. 
declaró firme la sentencia y se ordenó la ejecución de la resolución mencionada. Ni que decir tiene que las autoridades franquistas se incautaron de todas las pertenencias de Nelken que quedaron en su domicilio de Madrid ${ }^{18}$ : entre estas se contaban lienzos de Eduardo Chicharro y José Gutiérrez Solana; su correspondencia con Benito Pérez Galdós y el escultor Auguste Rodin; primeras ediciones dedicadas, etc.

Ya en 1942 el juez Pereda recibió el Sumario y ordenó se remitiera testimonio de la sentencia al presidente del Tribunal Nacional de Responsabilidades Políticas y Director General de Prisiones y Delegado de Estado para la recuperación de documentos, así como al Registro Central de Penados y Rebeldes y al Ministerio Fiscal ${ }^{19}$.

El triste epílogo de esta historia es uno de tantos del exilio republicano. Ironías del destino: pocos meses después de haber sido condenada por comunista, y debido a su enfrentamiento con Dolores Ibárruri, Pasionaria, Nelken fue expulsada del Partido Comunista. Esta defenestración supuso evidentemente para ella un alejamiento relativo de la esfera política. No obstante, y hasta su muerte en 1968, continuaría ligada a la causa antifranquista, a través de instituciones como la Ligue des Mutilés et Invalides de la Guerre $d^{\prime}$ Espagne en exil, el Patronato Pro-Presos de Franco o el Comité Español de Solidaridad con los Huelguistas de España.

Citaremos finalmente como testimonio de la nostalgia que siempre sentiría Nelken hacia España, así como de su rebeldía frente a la dictadura franquista, las primeras líneas de la letra que, junto a Miguel Hernández, escribió para el Himno a la República Española: "La Libertad nos ha dado su aliento;/ la Independencia, y el Pueblo su hogar;/ en el combate por un mundo hermoso,/ nos dan coraje la tierra y el mar./ ¡En pie, República Española,/ en pie con decisión! $[\ldots]^{20 "}$.

\section{Bibliografía}

Álvarez Lázaro, Pedro y José Manuel Vázquez Romero eds. Krause, Giner y la Institución Libre de Enseñanza. Madrid: Publicaciones de la Universidad Pontificia Comillas, 2005.

Casares, Francisco. Azaña y ellos. Cincuenta semblanzas rojas. Granada: Editorial y Librería Prieto, 1938.

Hernández, Miguel y Margarita Nelken (letra), Lan Adomian (música). Himno de la República Española ¿s.f.? AHN, Diversos/5, Leg. 3247, doc. n. ${ }^{\circ} 2$.

\footnotetext{
${ }^{18}$ Nelken, Presencias y evocaciones. Texto mecanografiado, México, 1947. AHN, Diversos/5 Leg. 3244, Doc. n. ${ }^{\circ} 4$.

${ }^{19}$ Se acompañan en el sumario posteriores acuses de recibo de estas autoridades, además de la transcripción o anotación de los datos relativos al proceso en sus diferentes registros o archivos.

${ }^{20}$ Miguel Hernández y Margarita Nelken (letra), Lan Adomian (música), Himno de la República Española ¿s.f.?, AHN, Diversos/5, Leg. 3247, doc. n. ${ }^{\circ} 2$.
} 
Hottinger Craig, Sylvia. "Las fotografías de mujeres entre las fotografías de origen masónico del archivo general de la Guerra Civil española". En Masonería Española. Represión y Exilios. Coordinado por José Antonio Ferrer Benimeli. Almería: Gobierno de Aragón, Departamento de Educación, Cultura y Deporte, 2009.

Jardón Pardo de Santayana, Pelayo. Margarita Nelken: del feminismo a la revolución. Madrid: Sanz y Torres, 2013.

Maeztu, Ramiro de. “¡Es la Nelken!”. $A B C, 1$ de febrero de 1935.

Mangini, Shirley. Las modernas de Madrid. Las grandes intelectuales españolas de la vanguardia. Barcelona: Ediciones Península, 2001.

Nelken, Margarita. "Carta abierta al Ministro de la Gobernación". El Día, 15 de julio de 1918.

Nelken, Margarita. "Una conversación con la doctora Arroyo de Márquez”. El Día, 26 de julio de 1918.

Nelken, Margarita. "La directora de la Escuela Normal". El Día, 2 de agosto de 1918.

Nelken, Margarita. La condición social de la mujer en España. Su estado actual, su posible desarrollo. Barcelona: Editorial Minerva, 1921. Reeditada con prólogo de M. A. Campmany. Madrid: CVS Ediciones, 1975.

Nelken, Margarita. Presencias y evocaciones. Texto mecanografiado. México, 1947.

Nelken, Margarita. El orden. Madrid: La Novela Roja, Semanario de literatura revolucionaria, 8 de julio de 1931. Reeditada por Talleres poligráficos en 1934. Incluida en el tomo Las novelas rojas, Estudio y antología de Gonzalo Santonja. Madrid: Ediciones de la Torre, 1994.

Neville, Edgar. "Margarita Nelken o la maldad". Y: Revista para la mujer, no. 8, septiembre de 1938.

Pujol, Juan. "Galería de monstruos: La serpiente con faldas". $A B C$, Sevilla, 17 de febrero de 1937.

Sánchez i Ferré, Pere. La Lògia Lealtad. Un exemple de Maçoneria catalana 1869-1939. Barcelona: Ed. Altafulla, 1985. 